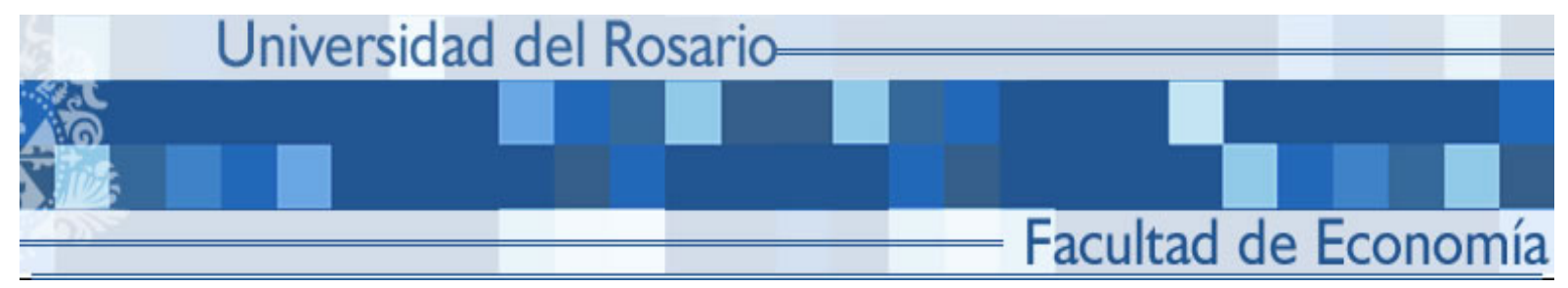

COMBATANT RECRUITMENT AND OUTCOME OF WAR

Ahmed Saber Mahmud

Juan Fernando Vargas

SERIE DOC UMENTOS DE TRABAJ O

No. 47

Septiembre 2008 


\title{
Combatant Recruitment and the Outcome of War*
}

\author{
Ahmed Saber Mahmud \\ Johns Hopkins University
}

\author{
Juan F. Vargas \\ Universidad del Rosario
}

\begin{abstract}
Why do some civil wars terminate soon, with victory of one party over the other? What determines if the winner is the incumbent or the rebel group? Why do other conflicts last longer? We propose a simple model in which the power of each armed group depends on the number of combatants it is able to recruit. This is in turn a function of the relative 'distance' between group leaderships and potential recruits. We emphasize the moral hazard problem of recruitment: fighting is costly and risky so combatants have the incentive to defect from their task. They can also desert altogether and join the enemy. This incentive is stronger the farther away the fighter is from the principal, since monitoring becomes increasingly costly. Bigger armies have more power but less monitoring capacity to prevent defection and desertion. This general framework allows a variety of interpretations of what type of proximity matters for building strong cohesive armies ranging from ethnic distance to geographic dispersion. Different assumptions about the distribution of potential fighters along the relevant dimension of conflict lead to different equilibria. We characterize these, discuss the implied outcome in terms of who wins the war, and illustrate with historical and contemporaneous case studies.
\end{abstract}

${ }^{*}$ We thank Hend Alhinnawi and participants at the 2007 LACEA Meeting and the WZB Conference on Causes and Consequences of Conflict. We are especially indebted with Johannes Muenster. Contact: asaber1973@yahoo.com, juan.vargas@urosario.edu.co 


\section{Introduction}

In the early 1980s the Shining Path launched an insurrection in Peru with the support of thousands of peasants. After an initial retreat, the army's counterattack in 1984 was led by the deadly Rondas Campesinas militias. Widespread fear created by the Rondas Campesinas led to massive desertions of insurgents from the Shining Path. This pattern soon became self-enforcing and the rebel group eventually lost the war to the government. Civil war in Peru lasted less than two decades and within that window it witnessed the sudden change from the rebels' relative success to their definite defeat.

Almost two decades before the onset of the Peruvian war, a low scale conflict was already maturating in Colombia with the formation of two rebel groups: FARC and ELN. Like its Andean neighbor, the Colombian government also promoted the formation of paramilitaries in the 1980s to contend the rapid expansion of the guerrillas. However, neither side ever generated sizable levels of desertion nor were them able to secure enough manpower to dominate the enemy by force. Civil war in Colombia persists to date after over four decades.

The average duration of civil wars has increased steadily since the end of the second World War, reaching 16 years in 1999 (Fearon, 2004). This trend suggests an increasing difficulty in ending intra-state conflicts. On the other hand, Toft (2006) argues that two thirds of the circa 120 civil wars that ended between 1940 and 2000 did son by military victory of either party. Why do some insurrections terminate soon while others are so much longer? What determines who wins the war? Why do some wars pendulate between the dominance of one group and the sudden recovery and take-over of the other? In this paper we think of these questions through a simple model of how the technology of recruitment of combatants determines the outcome of (an existing) war. Our model does not provide an account of what triggers the onset of conflict-whether ethnic cleavages, social grievances, economic opportunity, etc. (see Fearon and Laitin, 2003 and Collier and Hoeffler, 2004 for empirical analyses of the causes of civil war). Rather, we take conflict between two parties as given and analyze how the distribution of potential combatants along the most salient conflict dimension, whatever it be, together with the monitoring technology available to the groups' leaderships, shape the speed of conflict resolution as well as the likelihood that a specific party results victorious.

The analysis of the determinants of civil war duration has been predominantly empirical. Regan (2002) studied the effect of foreign intervention on civil war termination. Collier et al. (2004) and Fearon (2004) studied the impact of socioeconomic and political factors on the hazard of peace by looking at different type of Survival models, using respectively monthly and yearly data on civil war duration at the cross-country level. Montalvo and Reynal Querol (2007) also make use Survival models, but focus their analysis on the impact of ethnic polarization on the duration of war. Our paper lays out a simple theory that

relates the duration of war to the recruitment process and in this sense it does not directly give theoretical grounds to previous empirical literature. However, 
in line with Montalvo and Reynal-Querol, one result of our model is that polarization does make conflict less likely to be resolved in the short run. In this respect, our paper fits in the broader research agenda of Esteban and Ray, who have proved that when the population is divided into clusters with respect to some observable characteristic, and present substantial within-group homogeneity but between-group heterogeneity, the resulting polarization is closely linked to the generation of social tensions and violent unrest (Esteban and Ray, 1994 and Duclos, Esteban and Ray, 2004).

We build on the rent seeking literature as our model features a contest over an exogenous asset by two groups. The power of each group depends on the number of combatants the group is able to hire vis-a-vis the size of the enemy's army. By focusing on the recruitment problem, we introduce a moral hazard element to the baseline contest. When violence is at play, compliance is costly and combatants have incentives to shirk. They can also desert altogether and join the rival group. Performance cannot be enforced in court so the resulting relational contract has to be self-enforcing (MacLeod and Malcomsom, 1989). In our model this occurs through two constraints: a no-shirking constraint and a no-desertion constraint. When met simultaneously, these constraints make the compensation offered to each combatant incentive compatible.

Each group starts recruiting at its closest proximity and as the army expands, further recruitment takes place farther away. Monitoring then becomes costlier and non-compliance incentives get stronger. Hence, bigger groups have more power but less monitoring capacity to prevent defection and desertion. This general framework opens the floor for a variety of interpretations of what type of proximity matters for building strong and cohesive groups, ranging from ethnic distance to geographic dispersion.

While we focus on moral hazard, previous work on recruitment in civil war has also emphasized the problem of adverse selection. Weinstein $(2005,2006)$ identifies a rebel "resource curse" by which the abundance of resources facilitates recruitment on the basis of short-term rewards, attracting opportunistic soldiers who lack commitment and are not strongly identified with the cause of the rebellion. The absence of such resources, however, provides the incentives for a much solid recruitment practice, based on ideological commitment and the promise of some kind of reward if longer-term objectives are achieved.

The moral hazard problem of recruitment is not a novel idea. It first appeared in Polo (1995) who studied how internal cohesion shapes the effectiveness of organized crime enterprises. Gates (2002) draws from Polo's analysis, but focuses on recruitment in rebellion. In turn, we extend Gates' analysis by looking at the implications of the distribution of potential fighters along the relevant dimension of conflict. Indeed, different assumptions about the distribution of agents lead to substantially different set of equilibria. We characterize the universe of these, discuss the implied outcome in terms of who wins the war and how soon this happens, and illustrate the different cases with historical and contemporaneous case studies.

The paper is organized as follows: In section 2 we present the set up of the 
model and the set of constraints for recruitment to be incentive compatible. Section 3 characterizes the equilibria that result from different assumptions about the distribution of agents along the relevant conflict dimension, and discusses examples that illustrate our argument. Section 4 concludes and discusses several potential extensions of the model.

\section{The Model}

\subsection{Set Up}

Consider an infinite horizon polity in which two groups: the government $G$, and a rebel group $R$, fight every period over the control of an indivisible prize of value $K$, which could be interpreted as the rents from holding political power. ${ }^{1}$ The two groups prepare for war by recruiting fighters from the pool of available potential recruits. For that purpose, each group $i, i \in\{G, R\}$, offers a compensation $w_{i}$, a decision that takes place simultaneously. ${ }^{2}$ The expected utility for group $i$ at any given period is:

$$
U_{i}=S_{i}\left(n_{i}, n_{j}\right) K-n_{i} w_{i}
$$

where $S_{i}$, the probability of defeating the rival, is a concave function of both group's military capability, represented in turn by the number of combatants $n_{i}$ and $n_{j}$, where $\frac{\partial S_{i}}{\partial n_{i}}>0$ and $\frac{\partial S_{i}}{\partial n_{j}}<0$. In addition, we assume $S_{i} \in(0,1)$ for all values of $n_{i}$ and $n_{j}$. That is, neither group can be fully eliminated, even if a group runs out of combatants its leadership survives (for instance because it can effectively hide) so there is always some opposition.

Clearly, group $i$ will recruit combatants as long as the marginal cost, $w_{i}$, does not exceed the marginal benefit, $\frac{\partial S_{i}}{\partial n_{i}} K$. However, both the government and the rebels have to provide a compensations such that their fighters remain loyal. Non-compliance can take a variety of forms including refrainment from carrying-out the assigned task; secretly providing information to the enemy, or completely switching sides. Among these potential forms of noncompliance, we consider the first and the third possibilities, abstracting from the existence of spies.

Compliance is risky since combatants of group $i$ run into the risk of being killed by the enemy, which happens with probability $\left(1-\pi_{i}\right)$. That is, $\pi_{i}$ is

\footnotetext{
${ }^{1}$ The indivisibility of the prize makes it more likely that war occurs even under complete information (Fearon, 1995). In this paper, however, we don't model the decision on whether to engage in an armed dispute or not. Rather, we take such dispute as given an explore the conditions under which there can be a winner and the determinants of who the winner is.

${ }^{2}$ Armed groups in many civil wars often forcibly recruit in addition from-or as opposed to-providing material compensations. In this model one can think of $w$ as some sort of subsistence level reward, which does not have to be monetary (but can have some monetary component). Indeed, $w$ may pick up any food, shelter and uniform received by the combatant. The existence of $w$ does not prevent recruitment to be enforced by force. In fact, as it will become clear, in this model non-compliance is punished with death.
} 
the probability for a fighter from group $i$ of surviving a clash. We assume that the probability that a soldier from group $i$ gets killed in combat increases with the size of the enemy's army and is inversely related to the size of her own group's army. This implies $\frac{\partial \pi_{i}}{\partial n_{j}}<0$ and $\frac{\partial \pi_{i}}{\partial n_{i}}>0$. Further, we assume that $\pi_{i}\left(n_{i}, n_{j}\right) \in(0,1)$ for all values of $n_{i}$ and $n_{j}$. That is, there is always a positive probability of surviving.

Of course, the risk of being killed in combat does not exist if the task is not carried out. However, if left unpunished, non-compliance episodes may trigger waves of defection so we assume that combatants who get caught shirking are executed. Non-compliers are caught with probability $\left(1-p_{i}\right)$. That is, $p_{i}$ is the probability of getting away shirking.

Desertion in civil war is widespread and involves not only individuals but also larger groups. Among other reasons, forced recruitment may explain the lack of serious commitment to one's principal. A large share of the irregular armies across civil wars is composed by conscript soldiers (e.g. child soldiers). This is so even in cases in which there are additional elements to expect greater cohesiveness like the case of ethnic wars. For example, rebel "turncoats" have been used extensively by incumbent forces in different conflicts (Kalyvas, 2006). In our model, shirkers who survive capital punishment can either stay with their current group or defect altogether and join the lines of the enemy.

Given a set of compensations $W=\left\{w_{G}, w_{R}\right\}$ as well a set of probabilities $P=\left\{\pi_{G}, \pi_{G}, p_{G}, p_{R}\right\}$, fighters have the choice of whether or not to shirk, $s$, and if they decide to do so, whether or not to desert, $d$. The actions of fighters can be described formally as: $s: W \times P \rightarrow\{0,1\}$ and $d: W \times P \mid s=1 \rightarrow\{0,1\}$.

\subsection{Incentive Compatibility}

Let $\beta \in(0,1)$ be the rate at which the future is discounted. The instantaneous utility of a fighter of group $i$ who never shirks can be represented by the value function:

$$
V^{i}(s=0, d=0)=V^{i}(0,0)=\pi_{i}\left[w_{i}+\beta V^{i}(0,0)\right]
$$

where it is assumed that the value of being killed by the enemy, which happens with probability $\left(1-\pi_{i}\right)$, is 0 . This equation means that a complier who survives receives today's compensation plus the discounted continuation value. Note that, for fixed $W$ and $P$, the future choice will always be equal to the present one so $V(\cdot, \cdot)$ recurs with the same values for $s$ and $d$. Rearranging:

$$
V^{i}(0,0)=\frac{\pi_{i} w_{i}}{1-\beta \pi_{i}}
$$

The value of perpetual compliance to group $i$ is then increasing in the compensation offered by the group, in the probability of surviving in combat and in the rate at which the future is discounted. 
Shirkers who are not caught as such can stick to their original army or switch sides. The instantaneous utility of a shirker who stays is:

$$
V^{i}(1,0)=w_{i}+\beta\left[p_{i} V^{i}(1,0)\right]
$$

A shirker does not run today into the risk of being killed in combat so she fully enjoys the compensation $w_{i}$. But tomorrow he can get caught with probability $\left(1-p_{i}\right)$ and killed, the value of which is 0 . If she escapes punishment the value recurs. Rearranging:

$$
V^{i}(1,0)=\frac{w_{i}}{1-\beta p_{i}}
$$

The value of shirking is also increasing in the compensation and in the discount factor, but decreasing in the probability of being caught no complying.

Shirkers who also desert can be hired by the enemy or not. ${ }^{3}$ Let $q=\{0,1\}$ be an indicator for whether hiring occurs $(q=1)$ and $u$ be the outside option. We assume that if the deserter gets hired she then becomes a complier to her new group. ${ }^{4}$ Hence:

$$
V^{i}(1,1)=w_{i}+\beta\left(p_{i}\left[q V^{j \neq i}(0,0)+(1-q) \underline{u}\right]\right)
$$

A deserter is also a shirker so there is no present risk of dying in combat. If she avoids punishment from her original group she may or may not join the enemy. If she does so becomes a complier forever after. Using (2) this implies:

$$
V^{i}(1,1)=w_{i}+\beta p_{i}\left[q \frac{\pi_{j} w_{j}}{1-\beta \pi_{j}}+(1-q) \underline{u}\right]
$$

Because desertion implies shirking, its value is increasing in the wage of the left-behind group. It is also increasing in that of the receiving group, in the probability of escaping punishment, in the probability of surviving a combat against the former comrades and in the discount rate.

Recall that hiring a combatant requires that the marginal cost does not exceed the marginal benefit. In addition, to guarantee that fighters will stay in and comply, the compensation offered to fighters needs to be such that the value of complying must be at least as large as the best alternative option, either to shirk or to both shirk and desert:

$$
V^{i}(0,0) \geq \max \left\{V^{i}(1,0), V^{i}(1,1)\right\}
$$

\footnotetext{
${ }^{3}$ Deserters are highly valuable both as informants and to weaken the enemy by promoting further desertions. This is the case, for instance, of Colombian right wing militias who have absorbed many former guerrilla fighters (Gutierrez, 2004).

${ }^{4}$ Intuitively this captures the idea that deserters who are accepted in new groups are monitored more than other combatants to reduce the likelihood of enlisting spies. That is, $\left(1-\pi_{i}\right)$ is larger for received deserters and we assume that it is large enough as to rule out the incentive to desert back to the original army.
} 
Thus, a person will be hired by group $i$ if $w_{i} \leq \frac{\partial S_{i}}{\partial n_{i}} K$ and the no-shirking and no-desertion constraints are met. In short, $w_{i}$ has to be such that the following incentive compatibility condition (ICC) is met: ${ }^{5}$

$$
\frac{\pi_{i} w_{i}}{1-\beta \pi_{i}} \geq \max \left\{\frac{w_{i}}{1-\beta p_{i}}, w_{i}+\beta p_{i}\left[q \frac{\pi_{j} w_{j}}{1-\beta \pi_{j}}+(1-q) \underline{u}\right]\right\}
$$

The incentive compatible compensation offered to fighters by group $i$ is increasing in the probability of getting away shirking, $p_{i}$, in the probability of surviving combat against the former comrades if the fighter joins the enemy group, $\pi_{j}$, and in the wage paid by the opponent, $w_{j}$. It is decreasing in the probability of surviving combat given compliance to the current group, $\pi_{i}$.

Our basic set up draws on the principal-agent framework for recruitment laid out by Polo (1995) and followed by Gates (2002). However, in what follows we illustrate how small variations in the recruitment opportunities have radical implications for the outcome of the game. We illustrate the different potential equilibria with historical and contemporaneous case studies of civil war.

\subsection{Recruitment Process and Equilibrium Wage}

Consider a continuum of mass 1 of potential combatants distributed over the unit space $[0,1]$ according to some distribution $f(x)$, which can take any form (Figure 1 illustrates four potential shapes of $f(x)$ ). Let $z_{i}$ be the location of group's $i$ leadership in the unit space and $x_{f}$ the positioning of potential fighter $f$. Let $\left|x_{f}-z_{i}\right|$ be the distance between group $i$ 's leadership and fighter $f$ (Figure 2). Assume that $p_{i}^{f}$, the probability that fighter $f$ escapes punishment after defecting the task imposed by group $i$, is an increasing function of such distance. That is $\frac{\partial p_{i}^{f}}{\partial\left|x_{f}-z_{i}\right|}>0$. The further away a fighter is, the more difficult it is to monitor her so it gets easier to shirk and get away with it.

There is widespread evidence that geography shapes political allegiance in civil war. Drawing from her fieldwork in Nicaragua, Horton (1998) argues that peasants from peripheral regions with scarce military and political presence of the Sandinista state tended to align with the Contras, for their geographical proximity and hence influence. In contrast, in towns with effective state rule, no anti-Sandinista voice was heard. Seidman (2002) refers as "geographical loyalty" the tendency during the Spanish Civil War to side with the camp that controled the area where one lived; and Tone (1994) shows that during the Napoleonic occupation, geographical proximity to the French in the Spanish region of Navarra was inversely proportional to participation in anti-French insurgencies. Insurgents were predominantly recruited in frontier towns which the French could not effectively occupy.

\footnotetext{
${ }^{5}$ Note that if the compensation $w$ were exogenous, this set-up would be that of a classical rent-seeking model. Here, however, we endogenize $w$ in the sense that it has to be incentive compatible to ensure compliance.
} 
However, note that in this model 'distance' is not necessarily a geographical measure. The concept can be interpreted broadly, including for instance ethnic or ideological distance

The strategy space of the group leaderships is very simple. Given the set of probabilities $P=\left\{\pi_{G}, \pi_{G}, p_{G}, p_{R}\right\}$ as well as the location in the unit space of potential fighter $f$, and the implied monitoring capacity over her, given by the distance $\left|x_{f}-z_{i}\right|$, each principal decides whether to offer the incentive compatible compensation to $f$ or else refrain from hiring her.

Proposition 1 The wage offered by group $i$ to fighter $f$ in equilibrium ultimately depends on the number of $i$ 's own fighters relative to the number of fighters of the enemy, as well as on the distance between $f$ and $i$ 's leadership:

$$
w_{i}=w_{i}\left(n_{i}, n_{j},\left|x_{f}-z_{i}\right|\right)
$$

Indeed, this set of variables determines all the endogenous parameters of the incentive compatibility constraint: the probabilities of survival in combat $\left(\pi_{i}\right.$ and $\pi_{j}$ ) and the probability of getting away shirking $\left(p_{i}\right)$. The equilibrium wage offered by group $i$ is: increasing in $n_{j}$ because the probability of getting killed in combat increases with the size of the enemy's army; and increasing in $\left|x_{f}-z_{i}\right|$ because the probability of getting away shirking increases with distance. It is not unambiguous, however, what the effect of an increase in $n_{i}$ on the equilibrium wage would be. On the one hand the probability of surviving combat increases with the size of one's own army, so the required compensation can decrease; on the other, additional combatants must be hired farther away from $z_{i}$ which increases the monitoring cost so the opportunity cost of shirking has to increase.

Let's assume for simplicity that $R$ and $G$ are positioned at the extremes of the unit space, respectively at $z_{R}=0$ and $z_{G}=1$. Consequently, subject to the incentive compatibility constraint (5), the rebel leadership would like to hire fighters from $x_{f}=0$ onwards (i.e. to the right of the distribution) so as to maximize the detection of shirkers. If it hires all available combatants from 0 up to $x_{f}=x_{R}$, the number of combatants hired by the rebel group will be $n_{R}=\int_{0}^{x_{R}} f(x) d x$. Likewise, the government prefers hiring combatants from type $x_{f}=1$ onwards (to the left of the distribution). The size of the government army is ultimately: $n_{G}=\int_{x_{G}}^{1} f(x) d x$ (Figure 3 ).

Let $\bar{n}_{i}$ be the 'fighting deterrent' number of combatants of group $i$. Facing such an army, group $j$ finds it not profitable to recruit any more combatants, and group $i$ wins the war. That is $\bar{n}_{i}$ is such that:

$$
\frac{\partial S_{j}}{\partial n_{j}} K<w_{j}\left(n_{j}, n_{i}=\bar{n}_{i},\left|x_{f}-z_{j}\right|\right)
$$


Critically, we assume that deterrence is only possible if group $i$ hires more than half the total number of potential fighters: $\bar{n}_{i}>\frac{1}{2} \int_{0}^{1} f(x) d x=\frac{1}{2}$. That is, if the leadership of $i$ can hire beyond the median of the distribution.

Let $\bar{x}_{f}$ be the position in the unit space of the last combatant hired to achieve deterrence. Given the above assumption and the distribution of agents along the unit space $f(x)$ :

Proposition 2 i) For a symmetric distribution, $\left|\bar{x}_{f}-z_{i}\right|>\frac{1}{2}$

ii) For an asymmetric distribution, $\left|\bar{x}_{f}-z_{i}\right|$ can be $\leq \frac{1}{2}$

\section{Distribution Shape and the Outcome of War}

\subsection{Symmetric Distribution and Unique Outcome}

We first consider a case in which the population of potential combatants is distributed symmetrically along the unit space and investigate the conditions for a unique outcome, namely there is no clear winner in the short run: both groups hire combatants but none finds it optimum to recruit combatants up to the deterrent point, so complete dominance is not possible. Thus, at $\bar{n}_{i}$ :

$$
\frac{\partial S_{i}}{\partial n_{i}} K<w_{i}\left(n_{i}=\bar{n}_{i}, n_{j},\left|x_{f}-z_{i}\right|\right) \text { for } i \in\{R . G\}
$$

This case can arise, for instance, when there is a rough geography or low ethnic cohesiveness, characteristics that curb the ability to monitor the performance of fighters.

There are two potential reasons why such outcome can prevail:

Case 1 Neither group leadership can effectively monitor more than half of the total number of fighters.

Case 2 Even if monitoring is possible, it may not worth hiring a fighter.

The distinction between these two cases is subtle but in practice it has very relevant policy implications. Exogenous financial support to $i$ 's leadership (e.g. resources sent by a nationalistic diaspora or a foreign power) such that it can offer higher compensations and hence hire more combatants will not work under Case 1 since, given the scarce monitoring capacity, the new fighters (who are farther away from $z_{i}$ ) will have an incentive to shirk. However, Case 2 gives greater hope to external assistance. More resources will allow the group's leadership to employ more fighters and ultimately to take over the opponent. In sum, the finance from third parties can be a decisive factor in ending conflict only in some cases.

Consider Case 1. 
When monitoring technology is insufficient to hire fighters beyond the median, both groups have to be satisfied only with agents closer to them. That is, for group $i$ : $\left|x_{f}-z_{i}\right| \leq \frac{1}{2}$ for $i \in\{R, G\}$ and all $f$.

Which under symmetric distribution implies,

$$
\left|x_{f}-z_{i}\right| \leq \frac{1}{2}<\left|\bar{x}_{f}-z_{i}\right|,
$$

were the right hand side inequality follows from the first part of Proposition 2.

Combatants beyond the median of the distribution cannot profitably be employed. This implies that deserters from one group cannot be monitored by the enemy, and hence $q=0$. Thus (4) reduces to

$$
V^{i}(1,1)=w_{i}+\beta p_{i} \underline{u}
$$

and the ICC becomes:

$$
\frac{\pi_{i} w_{i}}{1-\beta \pi_{i}} \geq \max \left\{\frac{w_{i}}{1-\beta p_{i}}, w_{i}+\beta p_{i} \underline{u}\right\}
$$

Here, desertion is avoided altogether (i.e., $V^{i}(1,1)$ is not binding) whenever

$$
\frac{w_{i}}{1-\beta p_{i}}>w_{i}+\beta p_{i} \underline{u}
$$

Note that this is equivalent to assuming that the payoff from shirking is higher than the outside option, $V^{i}(1,0)>\underline{u}$.

We make this assumption for simplicity and thus rule out desertion as an equilibrium outcome. Note that all we need for this to hold is that the outside option be sufficiently small (close to zero, to which we normalize the value of death). ${ }^{6}$ This is generally the case in civil wars where non-combatants are military objectives of every group that does not acknowledge them as their supporters, which constraints civilians to join either one army or the other (see Kalyvas, 2006 and Vargas, 2008).

This assumption implies that the incentive compatible compensation has to offset only the value of a non-deserting shirker, or $V^{i}(0,0) \geq V^{i}(1,0)$.

Rearranging from the ICC, this implies:

$$
1 \geq \frac{1-\beta \pi_{i}}{\left(1-\beta p_{i}\right) \pi_{i}}
$$

However, this does not guarantee that all fighters lying between the group's core and the median will be hired. A fighter $f$ located at $x_{f}$ such that $(7)$ is not met, is not employable.

\footnotetext{
${ }^{6}$ This assumption is very likely to hold in civil wars in which armed groups take advantage of negative income shocks to recruit from the affected population. For instance this appears to be the case of the main coffee areas in Colombia during the late 1990s' coffee crisis, when the commodity lost $70 \%$ of its value in international markets (Dube and Vargas, 2008).
} 
Let $\underline{n}_{i}$ and $\underline{x}_{f}$ be respectively the number of recruits and the position of the last recruit such that:

$$
\frac{1-\beta \underline{\pi}_{i}}{\left(1-\beta \underline{p}_{i}\right) \underline{\pi}_{i}}=1
$$

where $\underline{\pi}_{i}=\pi_{i}\left(n_{i}=\underline{n}_{i}, n_{j}\right)$ and $\underline{p}_{i}=p_{i}\left(\left|\underline{x}_{f}-z_{i}\right|\right)$. Note that beyond $\underline{x}_{f}$, group $i$ cannot recruit further since it is not incentive compatible as defined by (7). Hence, compared to (6), a stronger condition for a unique outcome under a symmetric distribution, when monitoring is costly is:

$$
\left|\underline{x}_{f}-z_{i}\right| \leq \frac{1}{2}<\left|\bar{x}_{f}-z_{i}\right|
$$

In short, defection and desertion are not possible if the distribution of fighters along the unit space is symmetric and there is no recruitment beyond $\underline{x}_{f}$.

Consider now Case 2.

The monitoring technology may well be such that the leadership of group $i$ can hire fighters beyond the median such that $\frac{1}{2}<\left|x_{f}-z_{i}\right|$ for $i \in\{R, G\}$. However, even in this case, group $i$ may not want to hire up to $\bar{x}_{f}$ if the marginal payoff of hiring is lower than the marginal cost, or:

$$
\frac{\partial S_{i}}{\partial n_{i}} K<w_{i}\left(n_{i}=\bar{n}_{i}, n_{j},\left|\bar{x}_{f}-z_{i}\right|\right)
$$

Proposition 3 When potential fighters are distributed symmetrically along the relevant conflict dimension such that $\frac{1}{2}<\left|\bar{x}_{f}-z_{i}\right|$,

i) If monitoring beyond the median is not feasible, a sufficient condition for the unique outcome of the absence of a clear winner in the short run is:

$$
\left|\underline{x}_{f}-z_{i}\right| \leq \frac{1}{2}<\left|\bar{x}_{f}-z_{i}\right|
$$

ii) A necessary condition is that the marginal payoff of hiring the deterrent number of fighters does not offset the marginal cost (which can happen even if monitoring beyond the median is feasible):

$$
\frac{\partial S_{i}}{\partial n_{i}} K<w_{i}\left(n_{i}=\bar{n}_{i}, n_{j},\left|\bar{x}_{f}-z_{i}\right|\right)
$$

The unique outcome is more likely to occur when distributions have thicker tails. That is, this situation arises when the population is divided into sharp clusters, where geographic distance (or ethnic homogeneity, or political ideology, etc.) is small within clusters but large between them. When tails are thick, it is costlier to attain the minimum force necessary to overcome the rival, $\bar{n}_{i}$, since principals have to recruit further away from their epicenter, while the marginal net benefit remains the same: $\frac{\partial S_{i}}{\partial n_{i}} K-w_{i}$ (Figure 4). 
The Colombian civil war illustrates the difficulty of ending a conflict when neither group can outperform the enemy.

The conflict started in the early 1960s with the formation of largely rural peasant-based guerrillas in peripheral areas where the government had been traditionally absent. Throughout the 1970s and early 1980s, the conflict effectively served as a cold war proxy, with the Soviet block supporting the guerillas and the US supporting counter-insurgency efforts. From the late 1970s and during all the eighties military-backed paramilitaries became de facto counterinsurgency units, some of which are still active today.

Fighting in Colombia occurs mainly in rural areas where the rebels dispute the control of strategic strongholds with the state forces and the paramilitary. The polarization of the rural population in terms of compliance to one group or the other (often secured by coercion) has perpetuated the conflict and to date no group has secured nation-wide the numbers to shift the balance in their favor and trigger a redefinition of the balance of forces and ultimately the termination of war (either after some period of asymmetric fighting or by forcing a political negotiation).

\subsection{Symmetric Distribution and Multiple Equilibria}

The unique outcome of unresolved conflict is not the only situation that can take place when the distribution of potential combatants is symmetric. We now look at the multiple equilibria case when desertion takes place to an extent that one group secures enough manpower to defeat its adversary. Whether $R$ or $G$ is the winner is decided by expectations.

Recall that $w_{i}=w_{i}\left(n_{i}, n_{j},\left|x_{f}-z_{i}\right|\right)$ can be increasing or decreasing in $n_{i}$. It will be decreasing if the probability of being killed by the enemy in combat falls steeply enough such that it offsets the decrease in monitoring capacity. It will be increasing if the opposite happens, inducing group $i$ to offer a compensation that increases the opportunity cost of shirking and deserting. If the latter effect dominates there will be no desertion and we are back to the unique outcome scenario of unresolved conflict. But when a bigger army translates into lower wages, given the symmetry of the game, multiple equilibria can take place. This happens because there are increasing returns from recruitment.

In this situation, if potential (as well as actual) fighters believe group $i$ will win the war they will align with $i$ even if this implies deserting from group $j$. Unlike the previous case where both groups fail to recruit enough manpower to defeat the enemy, here in principle both armed groups should be able to recruit beyond the median of the distribution because they have the monitoring ability to do so. Whether $R$ or $G$ will end up enlisting the deterrent number of fighters and winning the war is contingent on expectations. Formally,

Lemma A necessary condition for multiple equilibria to exist is:

$$
\left|\bar{x}_{f}-z_{i}\right| \leq\left|\underline{x}_{f}-z_{i}\right|
$$


To see this notice that if the contrary were true such that $\left|\bar{x}_{f}-z_{i}\right|>$ $\left|\underline{x}_{f}-z_{i}\right|$, group $i$ would only be able to hire at best $\underline{n}_{i}<\bar{n}_{i}$. But, by definition $\bar{n}_{i}$ is the minimum army size necessary to decimate the opponent. So with an army of $\underline{n}_{i}$ group $i$ can never win.

On top of monitoring feasibility, fighters have to be profitably hired at $\bar{n}_{i}$, which implies: $\frac{\partial S_{i}}{\partial n_{i}} K \geq w_{i}\left(n_{i}=\bar{n}_{i}, n_{j},\left|\bar{x}_{f}-z_{i}\right|\right)$.

Proposition 4 When potential fighters are distributed symmetrically along the relevant conflict dimension such that $\frac{1}{2}<\left|\bar{x}_{f}-z_{i}\right|$, If $\left|\bar{x}_{f}-z_{i}\right| \leq\left|\underline{x}_{f}-z_{i}\right|$, there will be a multiplicity of equilibria if and only if:

$$
\frac{\partial S_{i}}{\partial n_{i}} K \geq w_{i}\left(n_{i}=\bar{n}_{i}, n_{j},\left|\bar{x}_{f}-z_{i}\right|\right)
$$

For a given monitoring technology, this condition is more likely to be met for distributions which have more density around the median (Figure 5). With such a distribution, the recruitment cost of hiring up to the deterrent level becomes lower while the marginal net benefit remains the same: $\frac{\partial S_{i}}{\partial n_{i}} K-w_{i}$. This logic is similar to that of models of democratic politics with swing voters. In these models, undecided voters who can ultimately support one party or the other, may turn out to be decisive for the political outcome. Similarly, in this model combatants can desert their army and join the former enemy to create a decisive imbalance of power, allowing one group to secure $\bar{n}$ fighters and hence win the war. Russell (1974) illustrates this point eloquently:

"(...) $[\mathrm{N}] \mathrm{o}$ mass rebellion can succeed without defection of some of the regime's armed forces. (...) [R] evolutionaries (...) must devote a great deal of thought to how to encourage defections from the police and the army." (Quoted in Gates, 2002).

In contrast, the multiple equilibria outcome is less likely for more polarized distributions as illustrated in the previous subsection.

Even if this game is infinitely repeated, the results are 'static' in the sense that wages are stationary (since they do not depend on the history of the game) and the distribution of the potential fighters is fixed. However, recruitment into armed groups is a dynamic phenomenon and from this perspective a more realistic model would be one that introduces a truly dynamic component. For instance, an unstable environment can be created by allowing the two principals to interact. We leave this extension for future work. However, this discussion implies that the above conditions are only necessary conditions for multiple equilibria. A truly dynamic model would be able to illustrate when the population can at all go back and forth between the two equilibria.

The analysis in this subsection characterizes a fundamentally unstable state of affairs. Dominance by one party can be reversed quickly. To enable such massive swing, the majority of the society must constitute a sizeable population 
who are not 'close' to neither of the warring extremes, or is somewhat in the middle. Even though the existence of such cases of multiple equilibria are not uncommon, the very lack of irreversibility makes them less prone to make it into the highlights of history. Nevertheless, we discuss some examples where, arguably, the outcome of revolutions was influenced by expectations-driven massive desertions.

Tilly (1973) describes how in Sicily in the $19^{\text {th }}$ century, after the closing of University in 1848, student protests led to small gatherings. This initiated further demonstrations that ended up with a few deaths. Soon, a full rebellion spread out and most of the island came to be under the control of the students. The end of the rule of the incumbent government was established when the liberal bourgeois and aristocrat joined the movement.

The triumph was, however, short-lived as the revolutionary coalition failed to maintain its cohesiveness to run the state. By 1849, the bourgeois and aristocrats abandoned the revolutionary cause helping the old government return. The outcome of the Sicilian Revolution was easily reversed: the liberal bourgeois and aristocrats were the critical mass of 'swingers' whose support determined the fate of the revolution.

In the early 1980s the Shining Path launched an insurrection in Peru with the support of thousands of peasants. After an initial retreat, the army's counterattack in 1984 was led by the deadly Rondas Campesinas militias. Widespread fear created by the Rondas Campesinas led to massive desertions of insurgents from the Shining Path as well as informants and collaborators from the peasantry. This pattern soon became self-enforcing and the rebel group eventually lost the war to the government. Civil war in Peru lasted less than two decades and within that window it witnessed the sudden change from the rebels' relative success to their definite defeat.

Something similar happened during the Zapatista Revolution in early $20^{\text {th }}$ century Mexico. Wolf (1973) describes the appearance in 1910 of a coalition of diverse groups of Mexicans who collectively rebelled against Porfirio Diaz. At the time, Diaz's rule was increasingly despotic and the opposition was furiously quieten. It was the combination of the speed of the outbreak and the diversity of groups represented by the coalition of rebels that made the revolution a successful one.

The Revolution started at Morelos and was carried out by both the peasantry and disaffected intellectuals with urban ties. A second hub of rebellion soon appeared in the north. There, the inequality of land holdings, the presence of cowboys and bandits and the abundance of cheap labor, fed into an overall discontent that soon made of the region one of the hottest spots of the Revolution. However, these clusters had limited regional influence and that was not enough to overturn Diaz's rule. A third force finally broke the deadlock: twenty six thousand men deserted from the constitutional army and joined the rebels, leading them to a final victory. 


\subsection{Asymmetric Distribution}

Consider the case in which potential fighters are distributed asymmetrically along the unit space. It is no longer true that: $\frac{1}{2} \int_{0}^{1} f(x) d x=\int_{0}^{\frac{1}{2}} f(x) d x=$ $\int_{\frac{1}{2}}^{1} f(x) d x$.

Suppose recruitment is not profitable beyond the median such that $\left|\underline{x}_{f}-z_{i}\right| \leq$ $\frac{1}{2}$ for $i \in\{R, G\}$. If the distribution was right-skewed and hence $\frac{1}{2} \int_{0}^{1} f(x) d x>$ $\int_{0}^{\frac{1}{2}} f(x) d x$, the Rebel leadership (located at $z_{R}=0$ ) would have smaller pool of potential fighters to hire from. Hence, even if the Government cannot recruit from the other half of the distribution so that $\left|\underline{x}_{f}-z_{G}\right| \leq \frac{1}{2}$, it may be able to reach enough manpower within its circle of (incentive-compatible) influence to defeat the Rebel group. This will happen when:

$$
\int_{\underline{x}_{G}}^{1} f(x) d x \geqslant \bar{n}_{G}>\frac{1}{2} \int_{0}^{1} f(x) d x
$$

However, this is only a sufficient condition. It is necessary that the Government finds it profitable to hire $\bar{n}_{G}: \frac{\partial S_{G}}{\partial n_{G}} K \geq w_{G}\left(n_{G}=\bar{n}_{G}, n_{R},\left|\bar{x}_{f}-z_{G}\right|\right)$, and the Rebel finds it not profitable to hire $\bar{n}_{R}: \frac{\partial S_{R}}{\partial n_{R}} K<w_{R}\left(n_{R}=\bar{n}_{R}, n_{G},\left|\bar{x}_{f}-z_{R}\right|\right)$.

So the only equilibrium under this case is when the government wins. Thus, when the majority of potential fighters is closer to the Government (and recall that this is not necessarily a geographical statement) a successful rebellion is unlikely.

Naturally, if the distribution is left-skewed so that $\frac{1}{2} \int_{0}^{1} f(x) d x<\int_{0}^{\frac{1}{2}} f(x) d x$, the same logic used above would lead us to claim the Rebel group as the winner (Figure 6). Hence,

Proposition 5 When the pool of potential fighters is distributed asymmetrically so that $\left|\bar{x}_{f}-z_{i}\right|$ can be $\leq \frac{1}{2}$, group $i$ will win if:

$$
\frac{\partial S_{i}}{\partial n_{i}} K \geq w_{i}\left(n_{i}=\bar{n}_{i}, n_{j},\left|\bar{x}_{f}-z_{i}\right|\right)
$$

while,

$$
\frac{\partial S_{j}}{\partial n_{j}} K<w_{j}\left(n_{j}=\bar{n}_{j}, n_{i},\left|\bar{x}_{f}-z_{j}\right|\right)
$$

This suggests that if the Government is 'close' to the majority the population, any attempt of revolution can easily be thwarted. While if it maintains a distance, revolution will become more imminent.

Why some societies are prone to rebellions while others seem to be immune has been studied by Moore (1966): 
"A highly segmented society that depends on diffuse sanctions for its coherence and for extracting surplus from the underlying peasantry is nearly immune to peasant rebellion. On the other hand, an agrarian bureaucracy or a society that depends on central authority for extracting the surplus, is a type most vulnerable to such violent outbursts."

This quotation suggests that strong centralized governments generate distance from the peasantry, thereby enabling the rebels to recruit from the periphery. In contrast, maintaining close ties with the villagers makes it more difficult to create a viable opposition.

This contrast is evident when we compare the history of China and Japan in the wake of the $20^{t h}$ century. While in China there was a centralized authority, Japan had an established feudal system. Even though imperial Japan had strong central administration and the advent of commerce withered the power of traditional landowners, the country was designed to serve the interest of the imperial rule. There, in sharp contrast to the case of China, villagers maintained a close link with the landowners: A Japanese village was also a community in symbiosis with the prevailing authority. In this sense, the 'distance' between the peasants and potential rebels was larger than the distance between the peasants and the landlords. Indeed, despite numerous sporadic rebellions during the Tokugawa period, an epoch making revolution failed to exist.

Imperial China, on the other hand, got rid of the landed aristocracy and former landlords eventually turned into scholarly administrators steeped into the Confucian ideal. This widened the 'distance' between the central administration and the peasants. A Chinese village was only a collection of independent homes who did not have much strong ties with the land, making migration more likely. This too the rebels to recruit and mobilize combatants to strategic places determining the outcome of the Chinese revolution.

\section{Discussion}

Contrary to Marx's prediction, revolutions seem to have taken place mostly in peasant societies, not in industrial settings. Many have sought to explain this apparent contradiction. According to Calhoun (1988), peasant societies retain the social capital that overcomes free rider problems and hence facilitate rebel movements. In contrast, urban workers in industrial clusters lack such ties and such movements become less likely. In contrast, Moore (1966) emphasizes the absence of the monopoly of violence inherent to primarily agrarian societies. To Wolf (1973), in turn, revolutions get momentum when capitalism has attenuated the power of rural landlords, weakening traditional elites.

This paper brings forth a potentially complementary explanation. Here, what matters for a successful revolution is the relative support of the (exogenously distributed) population. This is so regardless on whether the conflict is 
driven by ethnic, religious, ideological, class, or political grounds. Relating our model to the discussion above, because industrial labor is primarily urban, it is close to both capitalists and the government. This proximity to the 'incumbent' leaves little room for a rebel leadership to form a critical mass of recruits without avoiding the wrath of the establishment. On the other hand, if the rebels can recruit successfully and monitor a large army, a successful rebellion is more likely and hence the transformation of society. As exemplified by the cases of Northern Mexico and Southern China, geographical distance plays a crucial role. These places became hot-spots for recruitment precisely because they are distant from the center. If the peasantry however remains in close association with the landed elite, as in Japan during Togukawa period, rebellion becomes an unlikely event.

In addition, when both the government and the rebel leadership can garner moderate support from different segments of the society, the conflict is less likely to be resolved in the short run. This is the case of the long-lasting, low intensity Colombian Civil War. Yet in some other cases, massive expectationdriven shifts in loyalty from one principal to the other may be decisive for victory. Indeed, not all successful revolutions were carried-out entirely by the frontier residing peasantry. In the Mexican case, the final victory was achieved by a civilian-military coalition. Algeria followed a similar suite. Even though the anti-colonial movement started from village-level recruitment of rebels, it was the external support of the armies of Tunis and Morocco that gave the decisive push to the revolution (Wolf, 1973). Such cases illustrate how a defecting group or an external power can strengthen the rebel movement. We do not treat the case of external support explicitly in our model.

Finally we would like to discuss some potential extensions to our model. Indeed, recruitment in civil war is to date largely understudied (with the exceptions of Gates, 2002 and Weinstein, 2006) and this paper can be considered part of a greater research agenda on the microfoundations of civil conflict. In section 3.2 we mention the possibility of a more dynamic model that would allow for explicit interactions between the two principals. Several other avenues for future research can be pointed out. First, in the present model the distance between principals and agents is exogenously given. It would be interesting to illustrate, in the case of a potential class-conflict, how the distribution of land and the presence of inequality can endogenize the distance to the principals. This will also explain the opportunity cost of joining the rebellion for each individual in terms of her land holdings. Relatedly, the position of the government and that of the rebel leader are exogenously fixed in this model, and the distance between the two groups is normalized to one. An interesting expansion would have the position of the principals be a decision variable. Second, in this model the population can only fight. However, the outside option, $\underline{u}$, could be explicitly modelled, for instance by introducing a production economy and hence the opportunity for the citizens to decide whether to join one armed group or work productively (as in Grossman 1991). Third, in the current model the principals do not have a budget constraint. Resources are implicitly assumed to be unlimited and the only constraints are the no-shirking and no-desertions conditions. 
A budget constraint can be introduced, for instance, by having each principal control some natural resource which provides an exogenous endowment. We abstract from this in order to emphasize the underlying moral hazard problem of recruitment. Indeed, introducing natural resources to the model can potentially bring interesting insights, especially if one allows for these to be predated by the other party. However, this would turn the focus of the paper from the substantive problem of moral hazard in recruitment of soldiers to that of the existence or not of some sort of "resource-curse". Likewise, the model abstracts from potential incentive compatibility problems of the principals. The promise to pay the incentive compatible wage, for instance, is assumed to be credible but in reality such promise may depend on, for example, whether the principal is winning or loosing the war.

\section{References}

Calhoun Craig J. (1988). "The Radicalism of Tradition and the Question of Class Struggle", in Taylor, Michael (Ed.), Rationality and Revolution. Cambridge University Press.

Collier, Paul and Anke Hoeffler (2004)."Greed and Grievance in Civil War" Oxford Economic Papers 56: 663-595

Collier, Paul, Anke Hoeffler and Måns Söderbom (2004). "On the Duration of Civil War" Journal of Peace Research 41(3): 253-273.

Duclos, Jean-Yves, Joan M. Esteban and Debraj Ray (2004). "Polarization: Concepts, Measurement, Estimation" Econometrica 72: 1737-1772.

Esteban, Joan M. and Debraj Ray (1994). "On the Measurement of Polarization" Econometrica 62: 819-852.

Fearon, James (1995). "Rationalist Explanations for War" International Organization 49(3): 379-414.

Fearon, James (2004). "Why Do Some Civil Wars Last So Much Longer Than Others?" Journal of Peace Research 41(3): 275-302.

Fearon, James and David Laitin (2003) "Ethnicity, Insurgency, and Civil War" American Political Science Review 97(1): 75-90.

Gates, Scott (2002). "Recruitment and Alliance: The Microfoundations of Rebellion". Journal of Conflict Resolution, 46(1): 111-130.

Grossman, Herschel (1991). "A General Equilibrium Model of Insurrections" American Economic Review 81(4): 912-921.

Gutierrez, Francisco (2004). "Recruitment in a Civil War: A Preliminary Discussion of the Colombian Case". Working Paper, Santa Fe Institute.

Horton, Lynn (1998), Peasants in Arms: War and Peace in the Mountains of Nicaragua, 1979-1994, Ohio Center for International Studies.

Kalyvas, Stathis (2006). The Logic of Violence in Civil War. Cambridge University Press.

MacLeod, W. Bentley and James M. Malcomson (1989). "Implicit Contracts, Incentive Compatibility, and Involuntary Unemployment" Econometrica 57(2): 447-480. 
Montalvo, Jose G. and Marta Reynal-Querol (2007) "Ethnic polarization and the duration of civil wars" Unpublished manuscript.

Moore, Barrington (1966). Social Origins of Dictatorship and Democracy. Beacon Press, Boston.

Polo, Michele (1995) "Internal Cohesion and Competition Among Criminal Organisations" in Gianluca Fiorentini and Sam Peltzman (Eds.) The Economics of Organised Crime, Cambridge University Press.

Reagan, Patrick (2002) "Third Party Interventions and the Duration of Intrastate Conflict" Journal of Conflict Resolution 46: 55-73.

Russell, Diana (1974). Rebellion, Revolution and Armed Force: A Comparative Study of Fifteen Countries with Special Emphasis on Cuba and South Africa. New York: Academic Press.

Seidman, Michael (2002). Republic of Egos: A Social History of the Spanish Civil War, University of Winsconsin Press.

Tilly, Charles (1973). "Does Modernization Breed Revolution?" Comparative Politics 5(3): 425-447.

Toft, Monica, D. (2006). "Peace through Security: Making Negotiated Settlements Stick" Unpublished manuscript.

Tone, John L. (1994). The Fatal Knot: The Guerrilla War in Navarre and the Defeat of Napoleon in Spain, UNC Press.

Vargas, Juan F. (2008). "Seeking to Survive: Territorial Disputes in Civil War and the Killing of Civilians". Unpublished Manuscript.

Weinstein, Jeremy (2005) "Resources and the Information Problem in Rebel Recruitment" Journal of Conflict Resolution 49(4): 598-624.

Weinstein, Jeremy (2006) Inside Rebellion: The Political Economy of Rebel Organization. Cambridge University Press.

Wolf, Eric (1973). Peasant Wars of the Twentieth Century. Harper \& Row Publishers. New York. 
Figure 1. Potential distributions of fighters

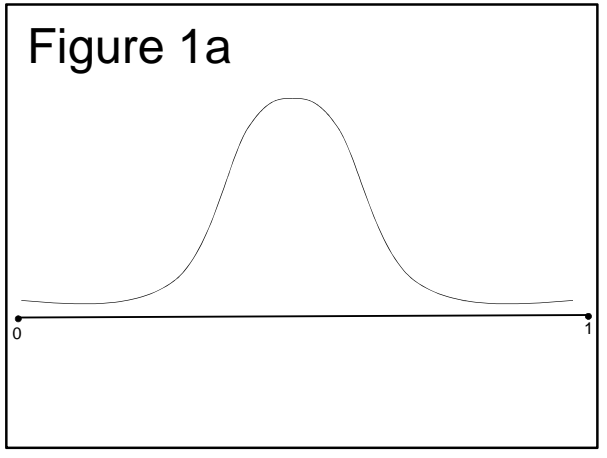

Figure 1b

Figure 1c

Figure 1d
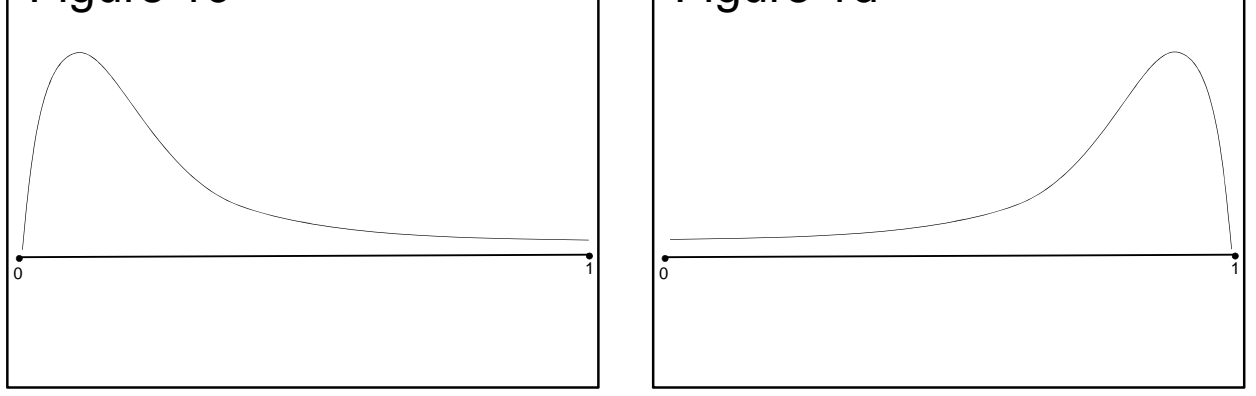
Figure 2. Distance between group $i$ and fighter $f$

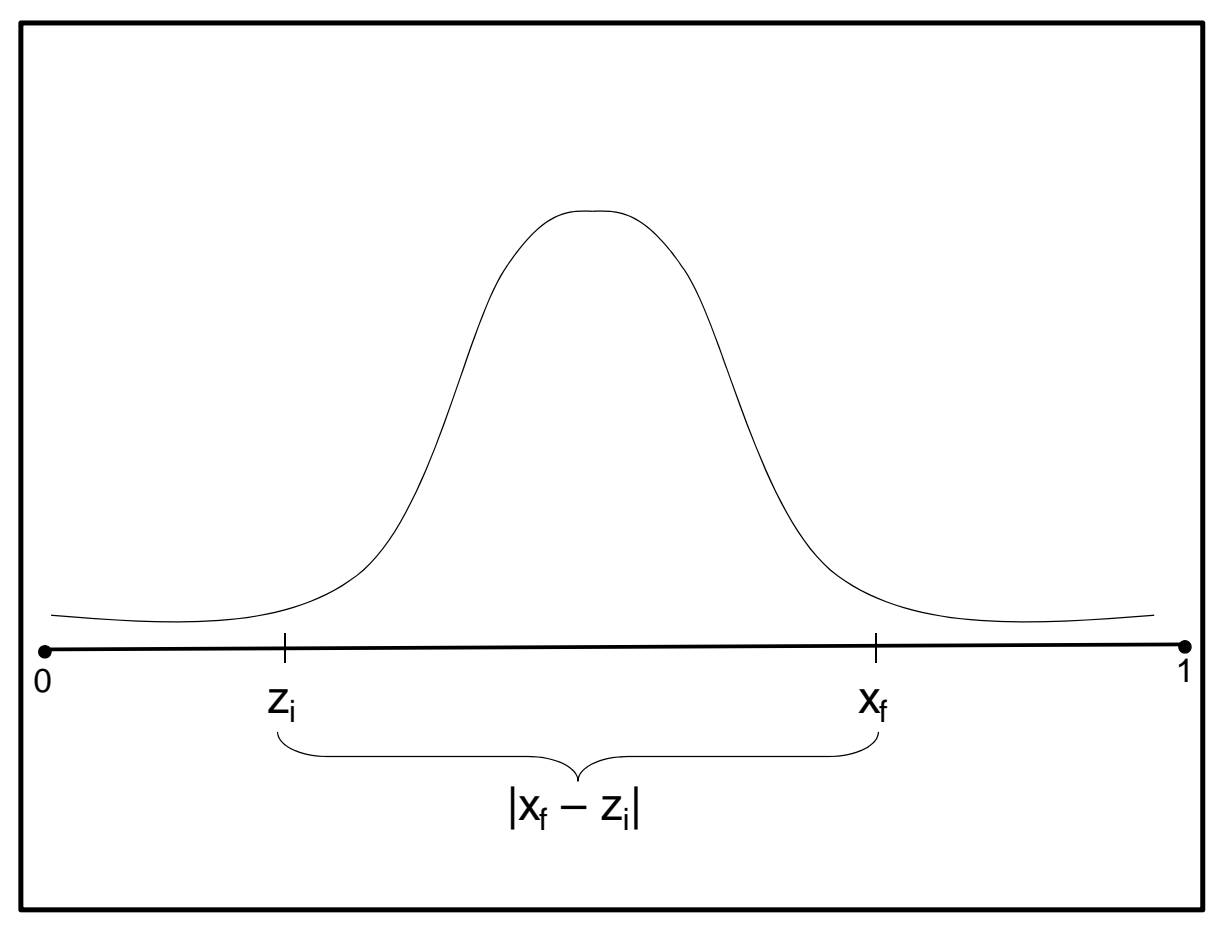


Figure 3. Size of Government and Rebel armies

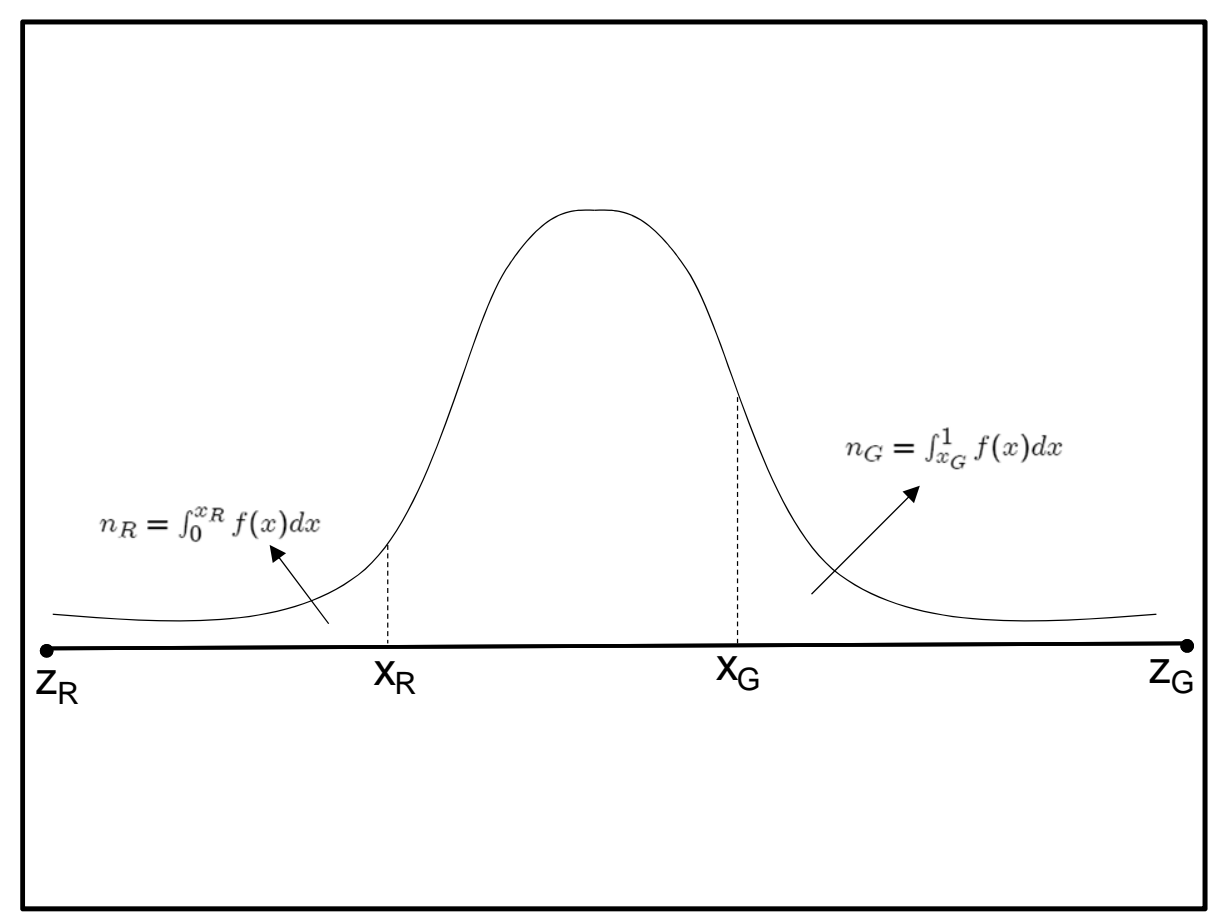


Figure 4. Polarization and unresolved conflict

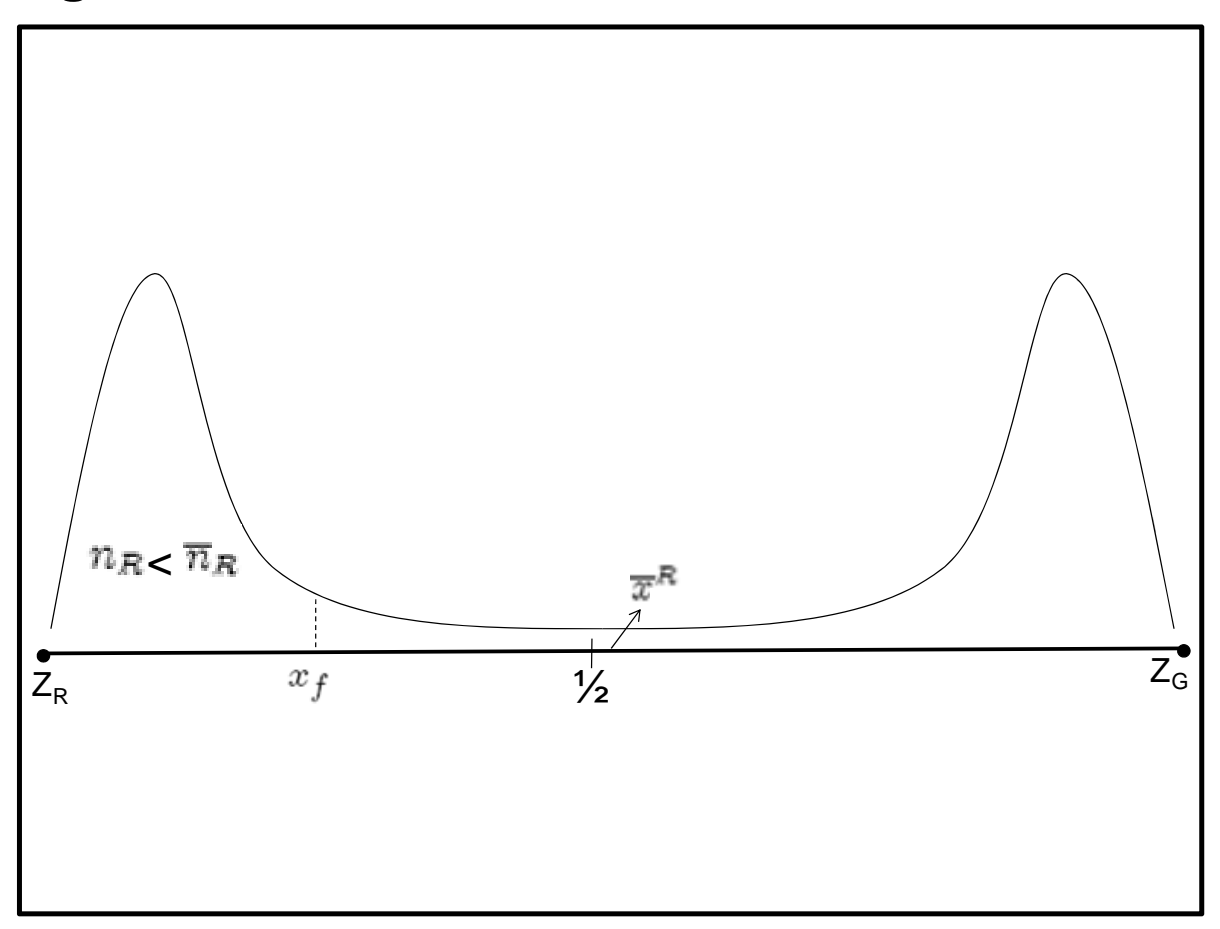


Figure 5. Expectations-based outcome

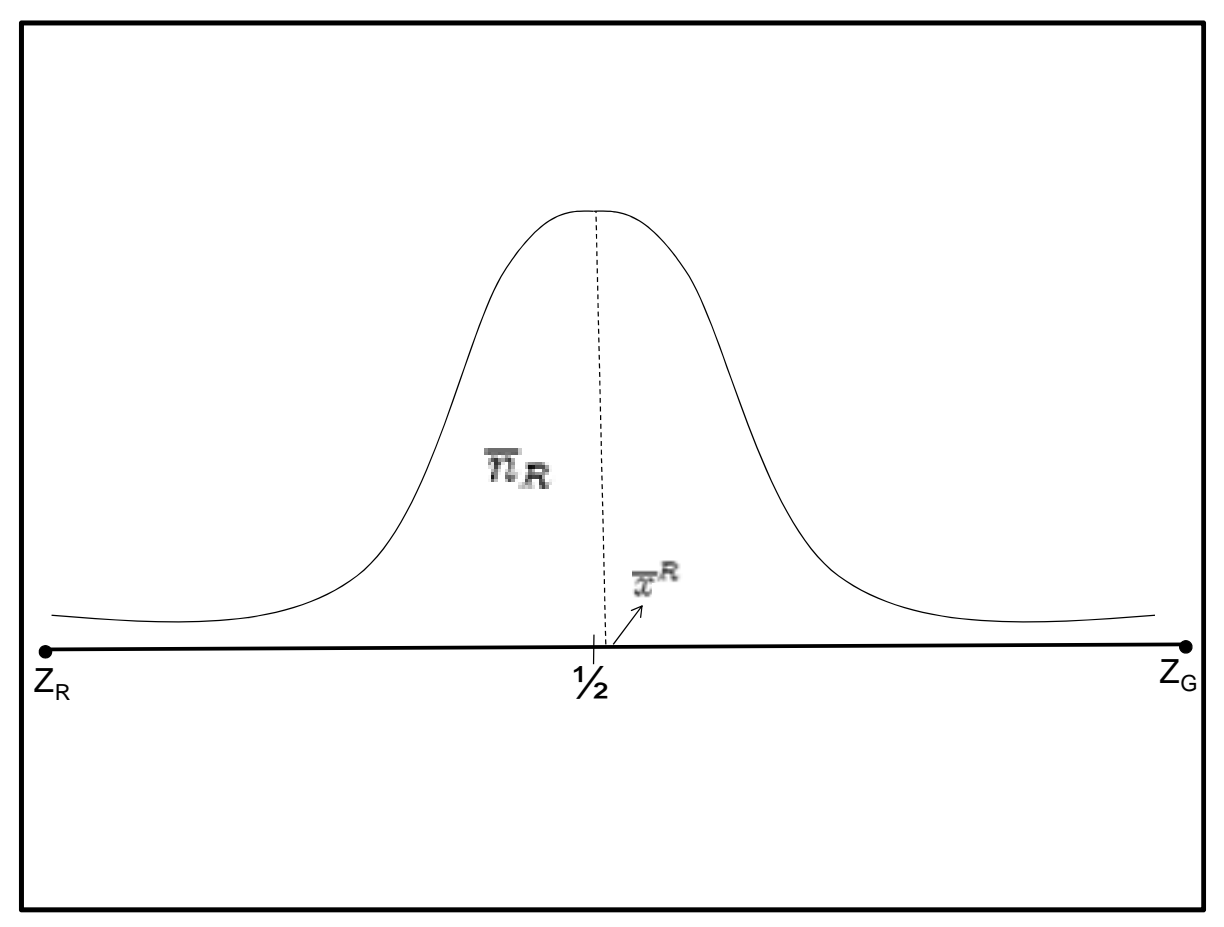


Figure 6. Victory by one side only

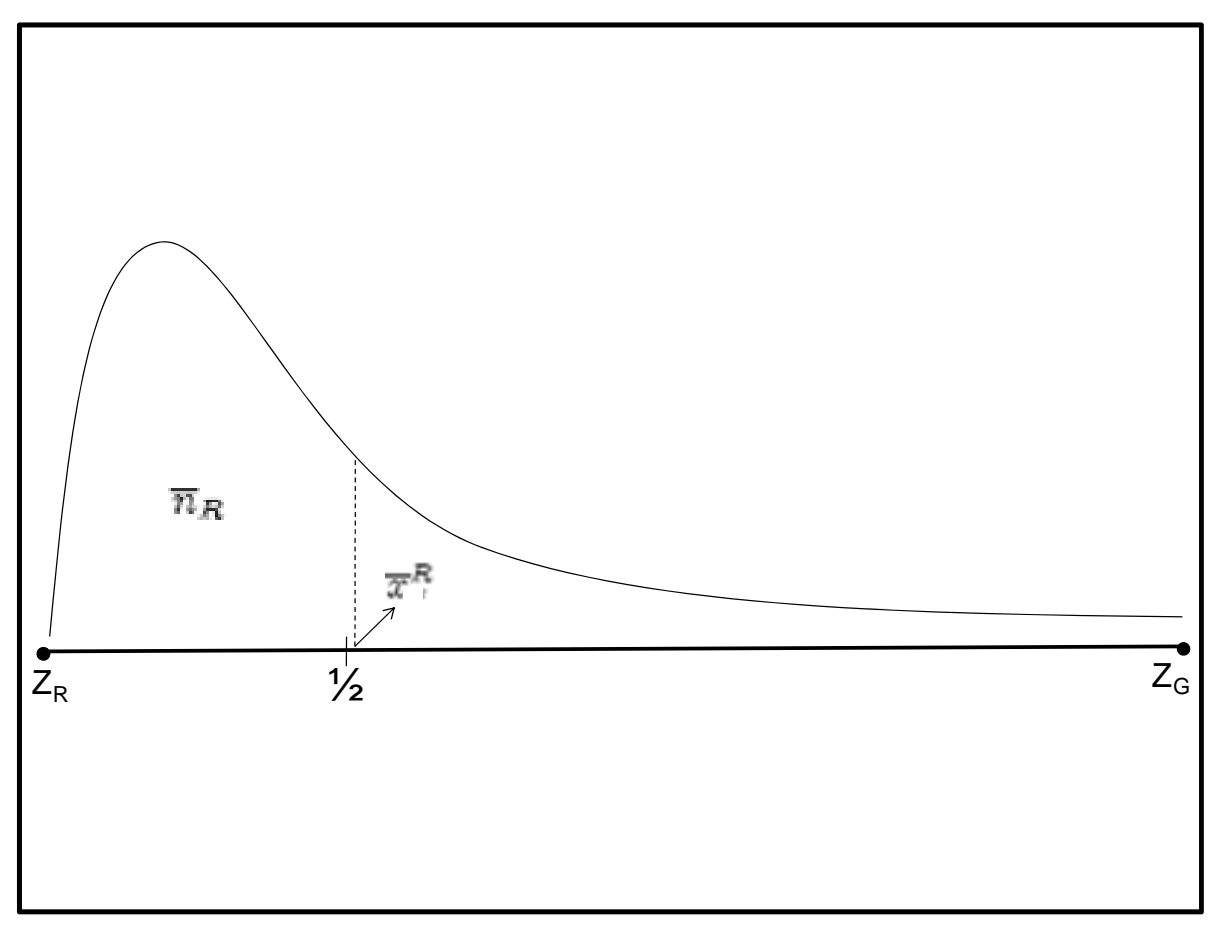

